\title{
Students' Lifetime Sports Consciousness Cultivation in College Sports Teaching
}

\author{
Ma Wenfeng \\ Sports Department of Jiangsu University \\ Zhenjiang, Jiangsu 212013
}

\begin{abstract}
High school education is an important stage of elementary education in our country, and is the key period in youth physical development. Health is helpful to the growth of adolescent health and ensures them smoothly finish high school. Set up lifelong sports consciousness in high school students not only improves high school students' physical quality, but promotes popular sports in the society, and it is the key to improve national physical quality. Physical training is ignored by high school students in today's high school sports education. Through school sports education, how to set up high school students' lifelong sports consciousness is an important task in high school physical education at the present stage.
\end{abstract}

\section{Key words: High school students; Lifetime sports; Sports consciousness}

High school sports' teaching is to improve students' health quality and promote all-round development of students. The development of modern science and technology brings convenience to people's life, and at the same time, also brings a series of health problems. Health problems become the world's topics. Lifelong education thoughts rise gradually in modern education and provide guidance for lifelong physical education teaching in high school. The current study of physical education problems makes teaching on the basis of the understanding of reality, which has a foundation and can improve the level of teaching. Cultivate high school students' lifelong sports consciousness and promote the comprehensive development of students. As education workers, in actual teaching, cultivate high school students' lifelong sports consciousness can not only confined to let students to participate in all kinds of sports training, but fundamentally change students' ideological understanding and view of sports and build up the idea of active exercise. As physical education workers, we should more actively update our teaching concepts and fuse the concept of lifelong sports into daily teaching work to improve students' awareness of physical exercise and lay a solid foundation for better promotion of lifetime sports consciousness.

\section{CURRENT HIGH SCHOOL STUDENTS’AWARENESS ON LIFELONG SPORTS CONSCIOUSNESS}

According to the investigation, China's high school students' overall understanding in physical exercise is not clear which caused little knowledge about the importance of physical exercise. This is the main cause of difficulties in lifelong consciousness sports training at the present stage. For most high school students at present stage, the so-called physical exercise is to deal with the pressure of entrance physical examination. This cognition ignores the importance of lifelong physical exercise and puts the cart before the horse. In addition, high school sports education lacks interest and factors such as unreasonable curriculum, which also cause students lack of sports awareness and sports interests. According to the survey in a school about high school students recognition degree about present sports teaching, only $42 \%$ accept the present teaching, and $8 \%$ don't accept, thus, how to change the present sports teaching mode is the key to cultivate high school students lifelong sports consciousness. With entrance pressure, high school students don't have good consciousness of physical exercise and they do not insist on physical exercise habit. A school's investigation shows that the number of daily exercise for a week is less than $6 \%$. The number of people who exercise once a week or don't exercise reaches as much as $48 \%$. Passive sports' training is the most common situation.

\section{THE PROBLEMS IN HIGH SCHOOL SPORTS TEACHING}

\section{A. Students'learning interest is low}

When high school students are doing sports activities in our country, they first imitate and then imitate the skills for practical application. In teaching, PE teachers tend to overestimate student's physical quality. After theory explanations, students just imitate, and they cannot flexibly use them. The national student physical education and health research results in 2014 and 2015 are shown as follows: 


\begin{tabular}{|c|c|c|c|c|c|c|}
\hline Gender & $\begin{array}{l}\text { quiet pulse } \\
\text { (times/min) }\end{array}$ & $\begin{array}{l}\text { Systolic blood } \\
\text { pressure } \\
\text { (MMHG) }\end{array}$ & $\begin{array}{l}\begin{array}{l}\text { Diastolic blood } \\
\text { pressure }\end{array} \\
\qquad(\mathrm{MMHG})\end{array}$ & $\begin{array}{l}\text { Forced vital } \\
\text { capacity (ml) }\end{array}$ & $\begin{array}{l}\text { Grip strength } \\
(\mathrm{kg})\end{array}$ & $\begin{array}{l}\text { Back } \\
\text { force } \\
(\mathrm{kg})\end{array}$ \\
\hline \multicolumn{7}{|c|}{ In 2014} \\
\hline Male & 78.3 & 119.4 & 74.8 & 3746 & 44.9 & 126.8 \\
\hline Female & 79.5 & 109.8 & 70.5 & 2482 & 26.3 & 66.8 \\
\hline \multicolumn{7}{|c|}{ In 2015} \\
\hline Male & 77.2 & 116.9 & 75.1 & 3748 & 45.8 & 128 \\
\hline Female & 77.6 & 107.2 & 70.1 & 2480 & 26.6 & 67.5 \\
\hline
\end{tabular}

The results of the survey show that high school students' health quality has rebounded, but compared to a few years ago high school students' physical quality, it is still in the decline stage. Sports teaching situation is not optimistic.

\section{B. School leaders make light of sports teaching}

Under the influence of traditional education, school leadership group makes light of sports teaching because once the idea is formed, it will have the characteristics of stability and not easy to change. Even though China has taken emphasis on teaching reform, yet, it is clear that the teaching reform achievement is not ideal. Especially for the attention of sports teaching, school leadership does not take sports teaching seriously. This will directly affect all related work of school sports, leading to poor sports teachers' teaching enthusiasm and irregular sports teaching. The first change of physical education teaching in schools is to change the concept of school leadership so as to make them play a leading role.

\section{Course setting is not reasonable}

The degree school attaches great importance to physical education and not sound infrastructure will directly affect physical education teaching effect. Teachers; teaching content in teaching is relatively fixed and single, lack of innovation spirit. Schools have no school-based curriculum. For example, in our school, there are no school-based curriculums such as swimming, table tennis and basketball lessons.

\section{The quality of teachers is not high}

Modern society requires lifelong learning, but some teachers hold conventional wisdom and often carry out teaching in accordance with traditional teaching methods. This is not conducive to teachers' lifelong development, and it will make the sports content behind The Times. These will influence the teaching effect. Another situation is that when choosing teachers, schools more think about teacher certificate, and simply test teachers' professional skills. Teachers only have sports knowledge, and their professional degree of psychology, pedagogy, physiology related knowledge is not enough. They must have independent emergency handling ability in actual teaching of sports.

\section{E. Students exercise time is little}

National policy regulates at least one hour each day for exercise, and teenagers have PE class every week, ranged from 2 to 4 section. In Jiangsu province high school students, physical exercise time less than an hour is about 33.7\%, more than an hour is only $11.4 \%$, and $17.4 \%$ literacy class encroach physical education. So students' physical exercise time is little.

\section{The main factors influencing high school students’ lifelong sports consciousness}

First of all, as the main body of sports, high school students know little about sport, and they do not understand the importance of sports. This is one of the important factors for that their sports consciousness is difficult to set up. On the one hand, in high school, physical development sex function of teenagers is more apparent on the body, which makes a lot of students refuse sports in technical sport due to too much worry. On the other hand because students lack of understanding of the purpose and significance of sports, they cannot experience the fun of sports. Most of the students take part in sports just on a whim, once interfered by outside factors; they will not be able to stick it out. 
Second, sports teachers' professional quality is one of the important factors which directly influence the formation of students' consciousness of lifetime sports. Generally speaking, teachers' physical education level directly affects students' interest in sports. In technical sports training, for example, if the teacher can make instructive training according to the specific situation of the students, it not only can improve the quality of training, also can improve teacher's prestige in students' heart so as to improve the enthusiasm of students to exercise and is conducive to the formation of lifelong sports consciousness. On the other hand, it can bring students' boredom to the physical education teacher even hinder the formation of students' sports consciousness. This requires that sports teachers should not only have solid professional knowledge, also know high school students' psychological characteristics and have skilled education teaching skills, etc.

Third, high school sports curriculum at the present stage is one of the limiting factors. In physical exercise, most girls like the movement with small coefficient difficulty and exercise intensity affected by psychological factors, and boys are easily affected by environment and like intense sports. Interest difference is so obvious in physical education at the present stage, but there's no way to handle that. There is a widespread phenomenon of "one size fits all" in school physical education at the present stage. A school survey found that $47.6 \%$ of the girls don't want to go to gym, and the reason is that $34 \%$ of the girls are afraid of substandard movement in sports, and $14 \%$ of the girls are fear of collision and competitive sports. In high school, students' physical development is basically mature, especially for senior girls. Sex characteristics obviously cause clumsiness. The concerns on skill movement and collision movement make the students' less high enthusiasm in the sports. Curriculum at present stage can't distinguish between different sports requirement situations caused by different physical condition and personality. This is the main cause for that most of high school students are not interested in sports.

\section{How to cultivate students' lifelong sports consciousness in the process of practical teaching}

Although at present there are many difficulties in setting up high school students' lifelong sports consciousness, in view of the causes of high school students' lack of sports consciousness, there is a clue to find out solution. Below we discuss effective countermeasures to cultivate and improve students' lifelong sports awareness in actual teaching process.

First of all, physical education teachers have to make reasonable choice suitable for high school sports teaching material. Students of different stages have different physiological and psychological characteristics. In sports teaching in high school, teachers need to select suitable teaching material content for high school physical education teaching. In teaching of sports, more teach physical exercise skills and methods. Sports teaching material should not only have rich knowledge, but also have fun and entertaining. Enhance students' interest in sports by studying sports knowledge, cause the attention of students for sports, and promote students' physical exercise.

Second, teachers' classroom teaching should update teaching idea and teaching method according to the actual teaching situation constantly. PE teachers should be aware that comprehensive professional knowledge and constantly expand the aspect of knowledge is the guarantee of well sports teaching. This requires physical education teachers to keep up with the pace of The Times, constantly update their sports information, strengthen their own professional sports knowledge, and help students to set up lifelong sports consciousness. In addition, traditional sports teaching ignore students' psychological development characteristics and simply do sports teaching. It is the important reason for the students' lack of interest in sports training. In the new era of sports teaching, physical education teachers need to update their teaching concepts and teaching methods and set up new sports education. Dare to break through the tradition, with the aid of abundant teaching equipment and information, not only teach sports knowledge and skills, but also arouse the students' interest in sports training in practical teaching, and lay a solid foundation for lifetime sports consciousness.

Third, cultivate students' interest in physical exercise is the key to set up students' consciousness of lifetime sports. High school students are in the adolescence. They have the psychological need for others' identity, eager to prove themselves, and their novelty curiosity is strong, and so on. Sports teaching can be combined with psychological characteristics for physical education teaching to stimulate students' interest in sports. For example, in sports teaching, design interesting and competitive games to improve students' sports participation.

Finally, reform the present high school sports teaching curriculum and practice open teaching. Open teaching is not let go of the teaching, but democratic teaching according to students' physical and psychological characteristics. Avoid traditional teaching of "one size fits all" and "same pace" phenomenon appears. For instance, students can choose projects and be divided into different classes. In this mode, students can choose sports training according to their own interest. Teacher can play a special skill and improve their business level. Students can enjoy exercise and play a special skill, and improve the awareness of physical exercise. Thus, open teaching improves the effect of physical education teaching and the importance of students' physical exercise consciousness.

\section{SUMMARY}

All in all, cultivating high school students lifelong sports consciousness cannot be completed overnight, and it requires more aspects efforts such as society, school, and students. Society should vigorously promote the importance of 
physical exercise in daily life, and school should reform the disadvantages of traditional sports teaching. Physical education teachers actively update education teaching idea. These may lay a solid foundation for lifetime sports consciousness cultivation in high school students.

\section{REFERENCES}

[1] Fang Yang. How to promote high school students to set up lifelong sports consciousness [J]. Journal of Jilin Education, 2007 (12).

[2] Dong Huining. The core of classroom teaching concept under new curriculum standard [J]. Journal of Qinghai Education, 2005, (12).

[3] Zheng Gonggang. The study of training students' lifelong sports awareness of countermeasures in high school physical education teaching [D]. Northeast Normal University, 2008.

[4] Zhao Wei. Analyses on the cultivation strategies of lifelong sports consciousness in high school sports teaching [J]. Journal of Contemporary Sports Science and Technology, 2014,07: 55-56.

[5] Xu Jingshan. On the cultivation of students' consciousness of lifetime sports in high school sports teaching [J]. Journal of New Curriculum Learning (Education), 2010, 12:92-93. 